\title{
Analisis dan Desain Sistem Informasi Penelitian dan Pengabdian Masyarakat (Simpenmas) Politeknik Negeri Lhokseumawe
}

\author{
Hari Toha Hidayat ${ }^{1}$, Haris Al Amin ${ }^{2}$, Mursyidah ${ }^{3}$, Atthariq ${ }^{4}$ \\ 1,2,3,4 Program Studi Teknologi Rekayasa Komputer Jaringan Politeknik Negeri Lhokseumawe \\ E-mail: haritoha@pnl.ac.id
}

\begin{abstract}
Information systems of research and community service need to be developed to improve the management of research outputs and community service outcomes by lecturers while making it easier to evaluate tertiary accreditation. This system was developed using the waterfall model. This article aims to describe the stages of system development consisting of: (1) investigating user needs; (2) data and needs analysis in the process of making a system; (3) design; and (4) implementation. The result is the need for a system that specifically can provide facilities for uploading research outputs and community service such as journal publications, textbooks/ texts, and scientific forum speakers. In addition to other mandatory menus, menus that are also being developed are the daily notes menu and the progress report menu. The design stages produce the design of the menu flow. The implementation stages of the research and community service information system use PHP language using the Laravel framework. Future studies need to test the use of systems that can use Apache jmeter and Selenium.
\end{abstract}

Keywords: information system, research and community services, analysis and design, waterfall model

\begin{abstract}
ABSTRAK
Sistem informasi penelitian dan pengabdian pada masyarakat perlu dikembangkan untuk meningkatkan pengelolaan hasil luaran penelitian dan pengabdian pada masyarakat oleh dosen sekaligus mempermudah dalam penilaian akreditasi perguruan tinggi. Sistem informasi penelitian dan pengabdian masyarakat (SIMPENMAS) tersebut dikembangkan menggunakan waterfall model. Artikel ini bertujuan untuk mendeskripsikan tahapan pengembangan sistem yang terdiri atas: (1) fase investigasi kebutuhan pengguna; (2) analisis data dan kebutuhan dalam proses pembuatan sistem; (3) desain; dan (4) implementasi. Hasilnya adalah kebutuhan sistem yang secara khusus dapat memberikan fasilitas mengunggah luaran hasil penelitian dan pengabdian pada masyarakat seperti publikasi jurnal, buku ajar/teks, dan pemakalah forum ilmiah. Selain menu wajib lainnya, menu yang juga dikembangkan adalah menu catatan harian dan menu laporan kemajuan. Tahapan desain menghasilkan perancangan alur menu. Tahapan implementasi dari sistem informasi penelitian dan pengabdian pada masyarakat ini menggunakan bahasa PHP dengan menggunakan framework Laravel. Penelitian selanjutnya perlu melakukan ujicoba penggunaan sistem yang dapat menggunakan apache jmeter dan selenium.
\end{abstract}

Kata kunci: sistem informasi, penelitian dan pengabdian pada masyarakat, analisis dan desain, waterfall model

\section{PENDAHULUAN}

Kemajuan teknologi informasi membuat segala pekerjaan menggunakan aplikasi. Dengan adanya teknologi informasi segala pekerjaan semakin dipermudah dalam hal pengurusan maupun monitoring dan evaluasi kegiatan. Keberadaan teknologi informasi ini semakin mempermudah untuk mewujudkan Good University Governance (GUG) dalam hal transparan dan akuntabel. Menurut UndangUndang nomor 20 tahun 2003 tentang sistem pendidikan nasional pasal 20 berisi mengenai perguruan tinggi berkewajiban menyelenggarakan penelitian dan pengabdian kepada masyarakat [1]. Pada Undang-Undang nomor 12 tahun 2012 mengenai pendidikan tinggi didalamnya juga mengatur kewajiban dosen yang menjalankan tridharma perguruan tinggi berupa pendidikan, penelitian dan pengabdian 
kepada masyarakat [2]. Sementara saat ini Kemenristekdikti mewajibkan bagi semua perguruan tinggi untuk mengelola penelitian dan pengabdian di perguruan tinggi masing - masing berbasis sistem informasi. Bahkan keberadaan sistem informasi untuk penelitian dan pengabdian kepada masyarakat menjadi salah satu persyaratan wajib yang perlu dimiliki perguruan tinggi di akreditasi [3].

Nilai pada poin penelitian dan pengabdian kepada masyarakat menjadi penilaian tertinggi bagi akreditasi institusi maupun program studi [4]. Kemenristekdikti juga menetapkan standar sistem informasi penelitian dan pengabdian kepada masyarakat bagi perguruan tinggi agar bisa membantu dalam hal pelaporan saat akreditasi. Dimana pada poin penilaian untuk akreditasi penelitian berada pada kriteria ke 7 dan ke 8 [3]. Selain itu, pada model akreditasi terbaru output daripada penelitian maupun pengabdian kepada masyarakat haruslah memiliki outcome bagi perguruan tinggi. Oleh karena penelitian dan pengabdian kepada masyarakat menjadi hal yang sangat penting. Menindaklanjuti hal tersebut, diperlukan sistem informasi untuk pengelolaan dan monitoring kegiatan yang dilakukan oleh para pelaksana dilapangan. Sistem informasi ini juga penting bagi para pengelola khususnya Pusat Penelitian dan Pengabdian Kepada Masyarakat (P3M) Politeknik Negeri Lhokseumawe untuk melakukan proses seleksi terhadap proposal yang diajukan untuk kegiatan penelitian dan pengabdian kepada masyarakat. Sistem informasi untuk penelitian dan pengabdian pada masyarakat dapat memudahkan pengelola dalam memonitoring pelaksanaan kegiatannya hingga pada tahap pembuatan laporan kemajuan maupun laporan akhir kegiatan.

Di dalam proses pembuatan P3M Politeknik Negeri Lhokseumawe memberdayakan keberadaan PPUPIK yang ada dilingkungan kampus. Dimana, pada Jurusan Teknologi Informasi dan Komputer telah memenangkan hibah PPUPIK yang bergerak dalam bidang pembuatan aplikasi, pengujian sistem serta pengadaan pelatihan pada bidang IT. PPUPIK merupakan pengabdian pengembangan usaha produk intelektual kampus. Melalui kegiatan PPUPIK perguruan tinggi berpeluang memperoleh pendapatan dan membantu menciptakan wirausaha baru. Selain itu, program PPUPIK diharapkan mampu mendorong perguruan tinggi dalam membangun akses yang menghasilkan produk jasa dan/ atau teknologi hasil ciptaannya sendiri. PPUPIK diharapkan mampu memiliki pendapatan tambahan secara mandiri untuk membantu menambah dana untuk operasional dikampus [5].

Terdapat beberapa penelitian sebelumnya terkait pengembangan sistem informasi penelitian dan pengabdian pada masyarakat [4], [6]-[9]. Pembeda antara sistem informasi penelitian dan pengadian pada masyarakat yang dikembangkan dalam penelitian ini dengan penelitian sebelumnya, selain pada konteks subjek, juga terdapat perbedaan pada perbedaan model pengembangan dan secara khusus adanya pendekatan PPUIK pada penelitian ini. Artikel ini membahas terkait analisis dan desain sistem informasi penelitian dan pengabdian pada masyarakat di Politeknik Negeri Lhokseumawe. Analisis dan desain yang komprehensif mampu mendapatkan spesifikasi produk pengembangan yang sesuai kebutuhan [10]. Produk pengembangan yang dimaksud dalam hal ini adalah sistem informasi penelitian dan pengabdian pada masyarakat (SIMPENMAS) di Politeknik Negeri Lhokseumawe.

\section{METODE}

Pengembangan sistem informasi ini dibangun menggunakan model yang bersifat sistematis dan berurutan yang disebut dengan waterfall model [11]. Tiap tahapan dalam model tersebut dilalui apabila tahapan sebelumnya telah selesai. Beberapa tahapan yang digunakan dalam waterfall model diantaranya: (1) fase investigasi kebutuhan pengguna; (2) analisis 
data dan kebutuhan dalam proses pembuatan sistem; (3) desain sistem dan database; (4) implementasi untuk pengerjaan pembuatan sistem; (5) testing untuk dilakukan pengujian sistem; dan (6) maintenance terhadap sistem apabila ada perubahan yang diinginkan oleh pengguna [12]. Artikel ini memaparkan sampai dengan tahapan implementasi hasil analisis dan desain. Analisis kebutuhan pengguna untuk sistem serta analisis data yang sudah ada dan digunakan oleh pihak pengguna selama ini dijadikan acuan dalam melakukan desain sistem.

Pada kegiatan ini yang menjadi objek pengguna adalah pusat penelitian dan pengabdian kepada masyarakat. Sementara objek kegiatannya adalah pembuatan sistem informasi penelitian dan pengabdian pada masyarak. Data primer dalam pembuatan sistem informasi penelitian dan pengabdian kepada masyarakat adalah berupa form laporan kemajuan dan laporan akhir, form catatan harian, form publikasi hasil penelitian dan pengabdian, form pengisian luaran berupa buku aja, form pengajuan proposal penelitian dan pengabdian kepada masyarakat, dan form isian anggota penelitian serta pengabdian. Data sekunder dari pembuatan sistem informasi penelitian dan pengabdian kepada masyarakat adalah komputer untuk menjalankan aplikasi, jaringan untuk membuka aplikasi yang berbasis web. Data pemenang penelitian dan pengabdian pada masyarakat.

Metode pengumpulan data terdiri atas observasi, wawancara dan studi pustaka. Kegiatan observasi dalam proses pembuatan sistem informasi penelitian dan pengabdian kepada masyarakat adalah memastikan kebutuhan yang akan diinginkan dari pihak P3M terhadap aplikasi yang akan dibuat. Selain itu, dalam proses pembuatan form maka dibutuhkan data langsung yang sudah digunakan oleh pihak P3M selama ini [13]. Proses wawancara juga dilakukan untuk menanyakan proses pengumpulan berkas apa saja yang biasa dilakukan oleh pihak P3M beserta persyaratan pendukungnya. Selain itu, untuk menanyakan proses setiap tahapan untuk pengumpulan berkas [13]. Mencari referensi yang relevan dari artikel jurnal ataupun buku yang mendukung terhadap proses pembuatan sistem informasi penelitian dan pengabdian masyarakat [13].

\section{HASIL DAN PEMBAHASAN}

Hasil tahapan pengembangan awal adalah diperolehnya kebutuhan sistem informasi, yaitu kebutuhan untuk mewadahi luaran-luaran hasil penelitian dan pengabdian pada masyarakat. Menu luaran tersebut menjadi media untuk mengunggah luaran-luaran yang wajib dipenuhi olehpara pemenang hibah penelitian dan pengabdian pada masyarakat. Luaran-luaran yang wajib diunggah dalam sistem informasi adalah: (1) publikasi jurnal; (2) buku ajar/teks; dan (3) pemakalah forum ilmiah. Melalui kajian, baik hasil observasi, wawancara maupun studi pustaka dirumuskan alur sistem informasi. Kajian tersebut dijadikan dasar perancangan sistem untuk ketiga luaran. Menu wajib dalam sistem ini diantaranya adalah berupa luaran dari hasil penelitian maupun pengabdian kepada masyarakat seperti publikasi di jurnal nasional, buku ajar dan sebagai pemakalah di seminar nasional.

Pada menu luaran berupa publikasi jurnal berisi data publikasi bagi para pemenang hibah penelitian. Dalam pengisiannya ada beberapa tahapan berupa isi data publikasi pada jurnal mana yang akan digunakan, kemudian dilanjutkan pengisian nama penulis artikel. Hal ini dibuat untuk mengetahui publikasi ilmiah yang dilakukan oleh pemenang hibah penelitian yang menjadi syarat wajib untuk luarannya. Luaran berupa buku ajar/teks dibuat untuk peruntukkan bagi para pemenang hibah penelitian dan pengabdian pada masyarakat. Selain publikasi jurnal bagi pemenang hibah penelitian terapan diwajibkan untuk buku ajar/teks. Dalam proses pengisian data ke dalam sistem yang dilakukan berupa isi data dosen sebagai penulis kemudian isikan data buku 
ajar/teks dimana didalamnya terdapat isian nomor ISBN dan percetakan yang akan menerbitkan. Selanjutnya yang menu luaran lainnya berupa pemakalah forum ilmiah. Dimana bagi pemenang hibah penelitian dan pengabdian pada masyarakat untuk mengikuti publikasi pada forum - forum ilmiah seperti pada seminar nasional maupun international. Perancangan sistem dalam pembuatan sistem informasi penelitian dan pengabdian pada masyarakat untuk luaran publikasi jurnal Gambar 1(a), untuk buku ajar/teks pada Gambar 1(b), dan untuk pemakalah forum ilmiah pada Gambar 1(c).

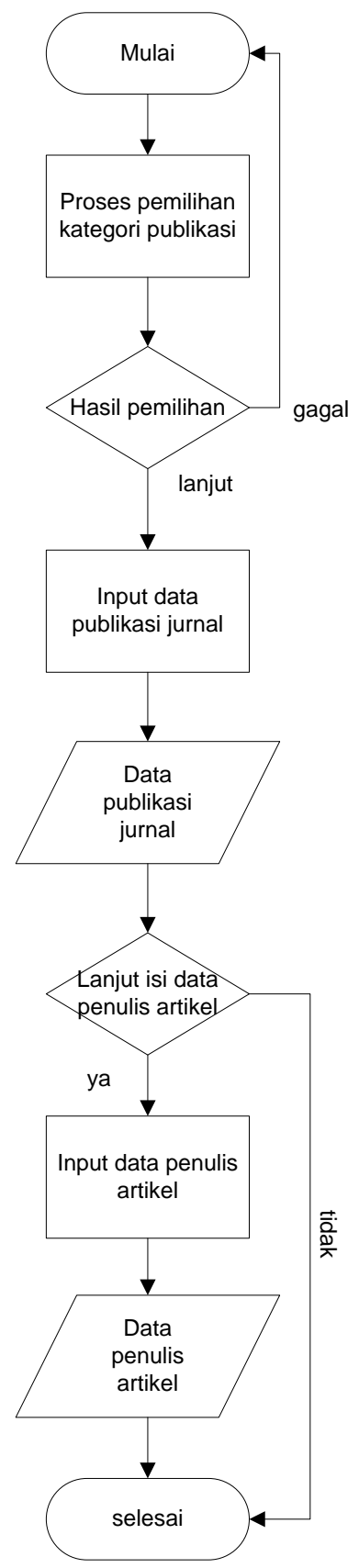

(a)

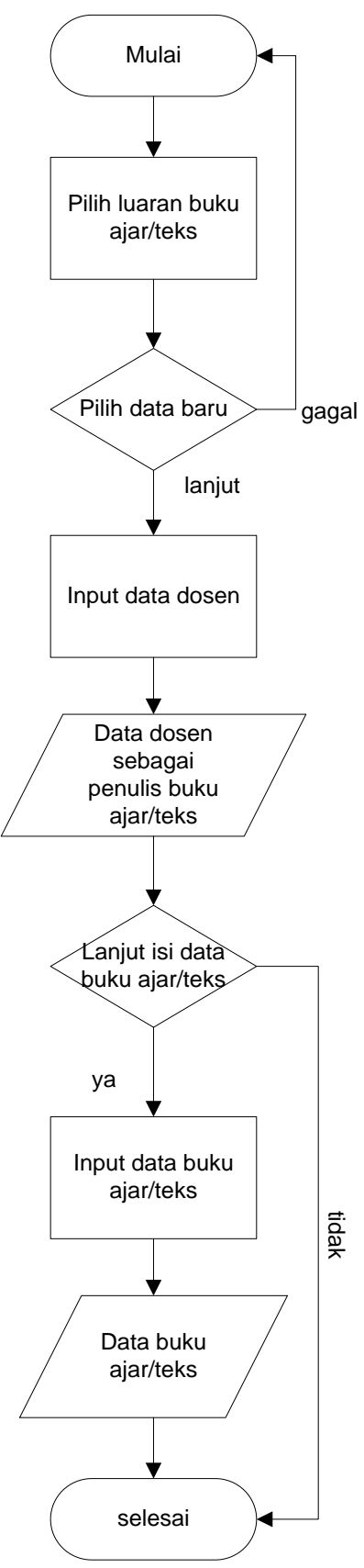

(b)

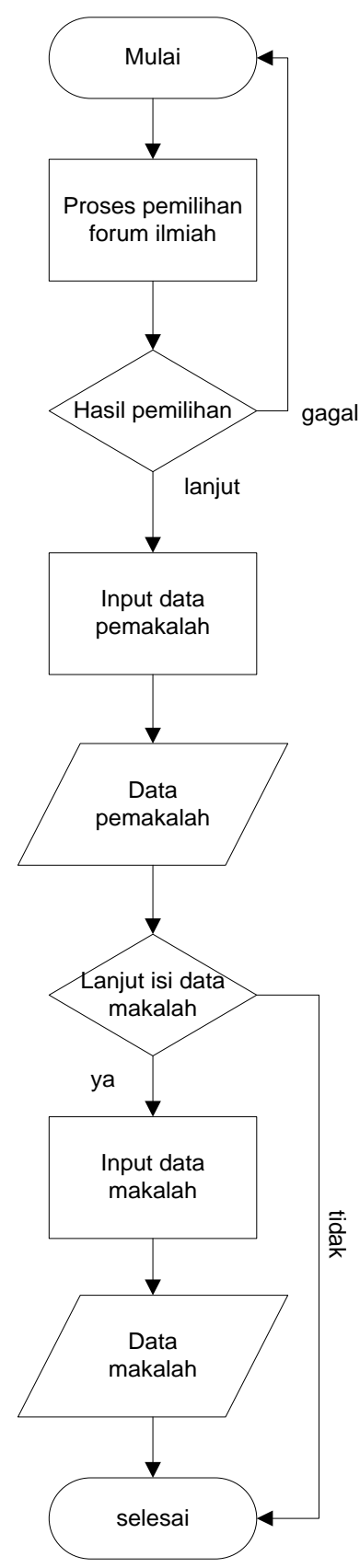

(c)

Gambar 1. (a) diagram sistem untuk data publikasi jurnal, (b) diagram alir sistem untuk data luaran buku ajar/teks, (c) diagram alir sistem untuk luaran pemakalah forum ilmiah 
Selanjutnya hasil perancangan diimplementasikan. Pembuatan SIMPENMAS ini dilakukan oleh tim programmer PPUPIK Hashtag Indonesia yang merupakan unit usaha dibawah Jurusan TIK yang membidangi pembuatan aplikasi, pengujian sistem dan pelatihan pada bidang IT. Adapun implementasi menu luaran publikasi jurnal dapat terlihat pada Gambar 2 dan Gambar 3.

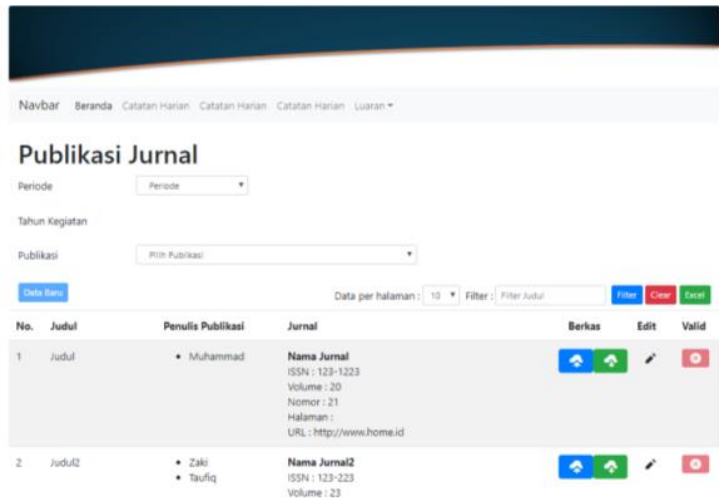

Gambar 2. Tampilan menu publikasi jurnal

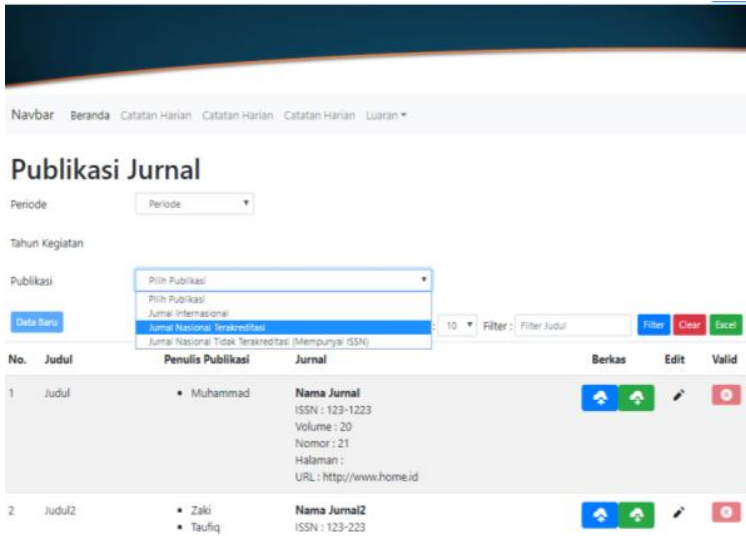

Gambar 3. Tampilan pilihan kategori publikasi

Pada Gambar 3 dapat terlihat beberapa kategori pilihan untuk publikasi pada jurnal international, jurnal nasional terakreditasi dan jurnal nasional tidak terakreditasi. Pada menu publikasi jurnal difasilitas menu untuk edit, unggah daan unduh serta pemberitahuan valid tidaknya file yang diupload ke dalam sistem. Selanjutnya menu luaran berikutnya yang terdapat dalam SIMPENMAS adalah menu buku ajar/teks yang dapat terlihat pada Gambar 4.

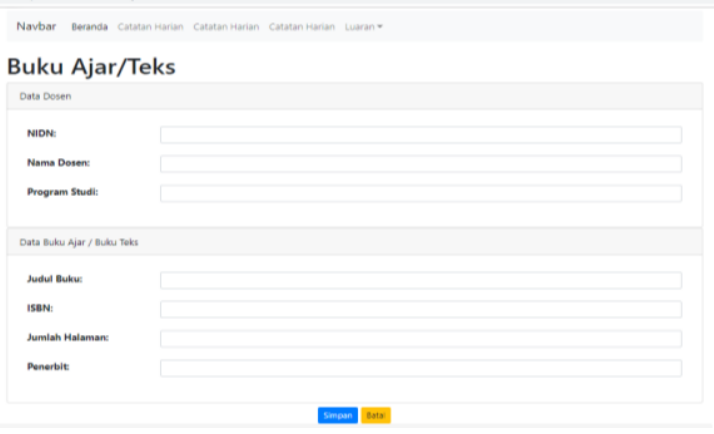

Gambar 4. Menu buku ajar/teks

Pada menu buku ajar/teks ini mengisikan data seperti nama dosen sebagai penulis kemudian mengisi data seperti judul buku, nomor ISBN dan nama percetakan yang menerbitkan buku ajar/teks. Berikutnya, menu luaran berupa pemakalah forum ilmiah dapat terlihat Gambar 5. Sebelum mengisikan data pemakalah forum ilmiah maka perlu dipilih terlebih dahulu pada kategori forum ilmiah apakah tingkat nasional atau internasional seperti yang terlihat pada Gambar 6 .

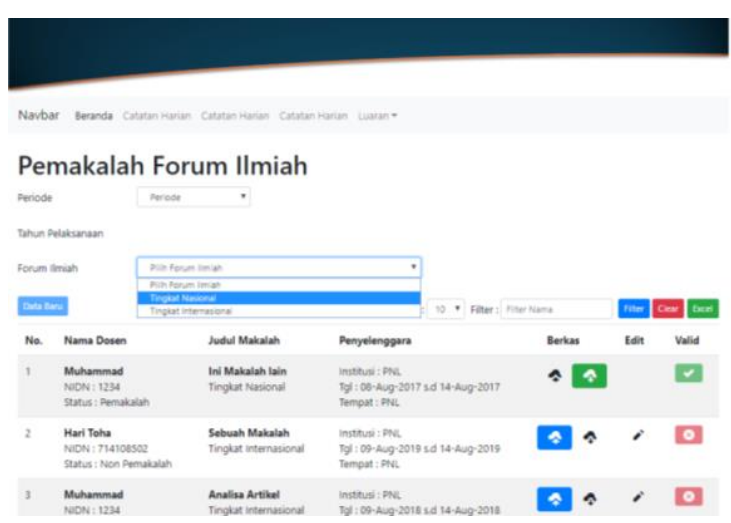

Gambar 5. Menu pemakalah forum ilmiah

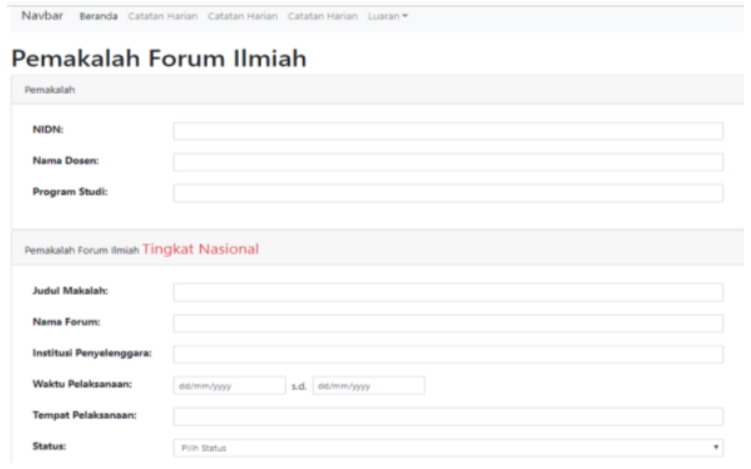

Gambar 6. Isian data pemakalah forum ilmiah 
Gambar 6 merupakan menu isian dari pemakalah forum ilmiah yang berisi isian data dosen sebagai penulis kemudian isian berupa judul artikel makalah, nama forum, institusi penyelenggara, waktu pelaksanaan dan tempat pelaksanaan. Tambahan dari menu luaran adalah menu catatan harian dan laporan kemajuan dan laporan akhir. Prosedur pengisian catatan harian adalah dengan mengupload bukti kegiatan baik berupa penggunaan dana maupun foto kegiatan yang telah dilakukan, Prosedur pengisian laporan kemajuan adalah berupa mengupload file laporan kemajuan dalam bentuk pdf.

Berdasarkan dari hasil implementasi analisis dan desain SIMPENMAS maka langkah - langkah dalam model waterfall telah dilakukan sampai dengan tahap keempat (implementasi). Tahap analisis sudah dilakukan dalam mengidentifikasi keinginan pihak P3M terhadap sistem, desain sistem telah dilakukan untuk membuat menu apa saja yang akan ada dalam SIMPENMAS, implementasi program dibuat dalam bahasa PHP dengan menggunakan framework Laravel. Penelitian selanjutnya adalah terkait tahap pengujian untuk uji coba penggunaan sistem. Untuk tahap pengujian menggunakan apache jmeter dan selenium sebagai tools untuk pengujian sistem.

\section{SIMPULAN}

Sistem informasi penelitian dan pengabdian pada masyarakat Politeknik Negeri Lhokseumawe telah berhasil sampai dengan tahap implementasi. Pada tahap awal, yaitu fase investigasi kebutuhan pengguna serta analisis data dan kebutuhan dalam proses pembuatan sistem digunakan dengan mengidentifikasi keinginan pihak P3M terhadap sistem. Hasil analisis kebutuhan pengguna adalah kebutuhan adanya fasilitas mengunggah luaran hasil penelitian dan pengabdian pada masyarakat. Hasil analisis kebutuhan sistem adalah diperlukannya menu luaran-luaran seperti publikasi jurnal, buku ajar/teks, dan pemakalah forum ilmiah. Tambahan menu lainnya adalah catatan harian dan laporan kemajuan dan laporan akhir. Tahapan desain menghasilkan perancangan alur menu. Tahapan implementasi menggunakan bahasa PHP dengan menggunakan framework Laravel. Penelitian selanjutnya perlu melakukan ujicoba penggunaan sistem yang dapat menggunakan apache jmeter dan selenium.

\section{DAFTAR PUSTAKA}

[1] S. N. RI, Undang-undang Republik Indonesia Nomor 20 Tahun 2003 tentang Sistem Pendidikan Nasional. Indonesia, 2003.

[2] K. S. N. RI, Undang-undang Republik Indonesia Nomor 12 Tahun 2012 tentang Pendidikan Tinggi. Jakarta, 2012.

[3] B. PT, Lampiran Peraturan Badan Akreditasi Nasional Perguruan Tinggi Nomor 3 tahun 2019 tentang Instrumen Akreditasi Perguruan Tinggi. Jakarta: Badan Akreditasi Nasional Perguruan Tinggi, 2019.

[4] Yanuardi and A. Jananto, "Rancang Bangun Sistem Informasi Penelitian dan Pengabdian Kepada Masyarakat," J. Teknol. Inf. Din., vol. X, no. 2, 2005.

[5] D. R. dan P. Masyarakat, Panduan Penelitian Dan Pengabdian Kepada Masyarakat Edisi XII Edisi Revisi 2019. Jakarta: Direktorat Riset dan Pengabdian Masyarakat,Direktorat Jenderal Penguatan Riset dan PengembanganKementerian Riset, Teknologi, dan Pendidikan Tinggi, 2018.

[6] R. Andrian, D. Sakethi, and M. Chairuddin, "Pengembangan Sistem Informasi Penelitian dan Pengabdian Dosen Jurusan Ilmu Komputer Menggunakan Metode Rational Unified Process (RUP)," J. Komputasi, vol. 2, no. 2, pp. 1-8, 2014.

[7] Hamzah, "Sistem Informasi Kegiatan Penelitian dan Pengabdian Kepada Masyarakat Universitas Respati Yogyakarta," J. Nas. Teknol. dan Sist. Inf., vol. 2, no. 2, pp. 17-26, 2016.

[8] S. Handayani, "Rancang Bangun Sistem Informasi Penelitian dan Pengabdian Dosen Fakultas Teknologi Informasi dan Komunikasi (FTIK) Universitas Semarang (USM)," J. Ilm. Infokam, vol. 13, no. 1, 2017.

[9] S. Dalis, "Rancang Bangun Sistem Informasi Lembaga Penelitian Dan Pengabdian Masyarakat Berbasis Web," Paradigma, vol. 19, no. 1, pp. 1-8, 2017. 
[10] G. P. Cikarge and P. Utami, “Analisis dan Desain Media Pembelajaran Praktik Teknik Digital sesuai RPS," ELINVO(Electronics, Informatics, Vocat. Educ., vol. 3, no. 1, pp. 92-105, 2018.

[11]R. S. Pressman, Software Engineering A Practitioner's Approach Seventh Edition. New York: Mc Graw Hill Higer Education, 2010.
[12]M. Shalahuddin and R. A.S., Rekayasa Perangkat Lunak. Bandung: Informatika, 2014.

[13]H. T. Hidayat, "Perbandingan Waterfall Model Dan Metode Generik Dalam Manajemen Proyek Perangkat Lunak Sistem Pengelolaan Dana Bantuan Operasional Sekolah (BOS) (Studi Kasus: MAN 1 Kota Lhokseumawe)," $J$. ECOTIPE, vol. 3, no. 1, pp. 25-30, 2016. 